\section{International Journal \\ of \\ English Studies}

IJES

http://revistas.um.es/ijes

\title{
The conventionalisation of contextual effects in middle structures
}

\author{
CASILDA GARCÍA DE LA MAZA* \\ University of the Basque Country UPV/EHU
}

Received: 10 May 2011 Accepted: 18 January 2012

\begin{abstract}
The presence of adverbial modification, affectedness, or the aspectual characteristics of the verb phrase have usually been invoked as principles governing the possibility for a verb to appear in the middle mode, as defended by Roberts (1987), Fagan (1992), Doron and Rappaport-Hovav (1991) and Levin (1993), inter al. This paper presents the results of a data collection project aimed at unravelling the issue of the conditions on middle formation. The data show how existing accounts are deficient in a number of ways and leave a wide range of data unaccounted for. Instead, the data reveal that pragmatic relevance has a major role to play in the matter and provide empirical support to defend the essentially "pragmatic value" (Green 2004) of the construction. Some of the formal properties of middles which had been formerly put down to syntactic constraints are then reanalysed in the light of this characterisation, including the apparent requirement for adverbial modification, which can now be approached from a fresh perspective.
\end{abstract}

\section{KEYWORDS:}

Middle construction, restrictions, gradient acceptability, contextual factors, acceptability ratings.

\section{RESUMEN}

La presencia de modificación adverbial, la afectación verbal o las características aspectuales de la frase verbal son algunos de los elementos que se han propuesto para explicar por qué algunos verbos pueden aparece en la construcción media (Roberts 1987, Fagan 1992, Doron and Rappaport-Hovav 1991 and Levin 1993, inter al.) Los datos presentados en este trabajo muestran que las propuestas existentes no son adecuadas y no explican una gran cantidad de datos. Los datos relevan que la relevancia pragmática desempeña un papel clave y ofrecen una base empírica que permite defender el "valor pragmático” (Green 2004) de la construcción. Esta caracterización obliga a reanalizar algunas de las propiedades formales de la construcción media que han sido atribuidas a restricciones de tipo sintáctico, tales como la aparente exigencia de presencia adverbial.

\section{PALABRAS CLAVE:}

Construcción media, restricciones, gradiente de aceptabilidad, factores contextuales, índices de aceptabilidad.

\footnotetext{
*Address for correspondence: Casilda García de la Maza. University of the Basque Country UPV/EHU, C./ María Díaz de Haro 68, 48920 Portugalete (Bizkaia), Spain. Tel: +34 946014 849; Fax: +34 946017 700; Email: casilda.garcia@ehu.es
} 


\section{INTRODUCTION}

The issue of the restrictions on middle formation has not always received enough attention in the literature. Keyser and Roeper (1984:383), for instance, quote examples like *French acquires easily or *The answer knows easily, and regard them as "grammatical in principle, although deviant on semantic terms". They also acknowledge that they have "no idea why these sentences are excluded”. It is true that, whereas some middles like This book reads well or Her new car drives beautifully are perfectly acceptable, others like Some children educate easily or This book reads are not (so) good English sentences. This paper tries to shed some light on the actual scope and nature of such constrains. It will proceed as follows: Section 2 reviews existing accounts of the restrictions on middle formation and presents the hypotheses that will be put to the test. Section 3 describes the data collection project and the methodology that was used. Section 4 presents and analyses the results. Section 5 contains a discussion of the results and comes back to reassess some of the features of middles in the light of the main findings of the study. Section 6 is a conclusion.

\section{EXISTING ACCOUNTS AND HYPOTHESES}

\subsection{Aspectuality}

Roberts (1987:207ff.) and Fagan (1992:64-100) argue that the aspectual properties of the verb phrase in question play a crucial role in determining its eligibility for middle formation. Both of them use the standard aspectual classification of predicates into states, activities, achievements and accomplishments (Vendler 1967; Dowty 1979; see also Comrie 1976:4151). According to Vendler (1967:100), accomplishments describe processes going on in time that proceed towards a "climax" or "terminus". It follows from this that verb phrases denoting accomplishments, like draw a circle, are meaningful in questions like How long did it take him to draw a circle? and that their progressive does not entail the perfect, so that John is drawing a circle does not entail John has drawn a circle. A sentence like John drew a circle for an hour does not entail that he drew a circle at every moment in that hour. Activities, as well as accomplishments, describe processes going on in time, but they do not proceed towards a climax, but rather "go on in time in a homogeneous way and any part of the process is of the same nature as the whole" (Vendler 1967:101). This explains why activities, like run, are not meaningful in questions like How long did it take him to run? and why the progressive entails the perfect (John is running entails John has run). The entailments of activity verb phrases with a for-phrase differ from those of accomplishment verbs. John was running for an hour entails that he ran at all times in that hour. States, like know, do not describe processes going on in time. Achievements, like states, do not describe processes going on in time, but, 
unlike them, they can be predicated of single moments of time. They can be recognized because they do not occur with for-phrases (*He noticed the painting for an hour), and are odd with the progressive (?? He is noticing the painting).

Roberts (1987:215) claims that middle formation is only available to accomplishments. The minimal pair in (1) (Roberts' example) is given as evidence. The contrast is explained because hit the glass is an activity and not an accomplishment.

(1) a. This glass smashes easily.

b. *This glass hits easily.

Fagan (1992:64-81) also maintains that middle formation is sensitive to the aspectual characteristics of the verb involved. However, she claims that activities, as well as accomplishments are eligible for middle formation. She bases these conclusions on the following three examples, whose verb phrases are activities, and which, she asserts, form acceptable middles:

(2) a. The car drives easily.

b. This pipe smokes nicely.

c. This piano plays easily.

\subsection{Affectedeness}

It is often claimed (Roberts 1987; Hale and Keyser 1987; Doron and Rappaport-Hovav 1991; Hoekstra and Roberts 1993; Levin 1993:26) that middles can only be formed from verbs whose objects are "affected" by the action expressed by the verb. The affectedness constraint is thus seen as responsible for the contrast in acceptability exhibited by the following sentences (from Hoekstra and Roberts (1993:201), their examples) in which neither the mountains nor anniversaries can be seen as affected or undergoing any change of state in any way:

(3) a. *The mountains see better after the rain.

b. *Anniversaries forget easily.

Claims in the opposite direction, however, also exist. Fagan (1992:65), on the basis of examples like those in (4) (her examples), in which the verbs read and photograph form acceptable middles, despite not having affected arguments, concludes that affectedness is not a relevant factor in middle formation. 
(4)
a. This book reads easily.
b. She photographs well.

\subsection{Semantic and pragmatic constraints}

Middles have been characterised as exhibiting the so-called "property reading” interpretation, which captures the intuition that the subject of a middle sentence is understood as responsible for the action denoted by the verb. A middle like Love stories read easily is indeed ascribing some property to love stories that makes them easy to read (see García de la Maza 2011 for an account of the semantics of the construction).

The idea of the subject's responsibility is present in a number of descriptive accounts of middles (Erades 1975, Van Oosten 1977), but it is Fagan who formulates it as a constraint on middle formation. She claims that together with the aspectual constraints discussed above, the notion of responsibility plays a role in the acceptability of middles, and that "only those verbs whose objects are perceived as responsible for the action denoted by the verb may appear in middles” (Fagan 1992:100). Yoshimura and Taylor (2004:310) also argue that "middle expressions are only viable to the extent that responsibility can be attributed, mainly, to the middle subject". They provide abundant examples to show that "the essence of middles lies in the "special way in which a subject referent is conceptualized in association with the semantics of the verb phrase” (p. 316). Fellbaum (1985:23) and Rosta (1995:132) bring in pragmatic considerations and point out that, in order for middles to be acceptable, they had to provide "newsworthy information". The dubious status of middles like Cars wash well can be put down to the relationship that holds between the properties of the subject and the action denoted by the verb. Under normal circumstances, and assuming no context, it is an inherent property of cars that they can be washed, and no newsworthy information is being provided by stating it.

The property reading and the idea of newsworthiness can be made to fall together and can be better explained from a relevance theoretic perspective (Sperber and Wilson 1995). In Relevance Theory, the notion of relevance is characterised in terms of contextual effects. An utterance is said to be relevant in a context "if and only if it has some contextual effect in that context” (Sperber and Wilson 1995:122). For newly presented information to have contextual effects, means for it to add to, or interact with, old information in a certain way, for example, by making it is possible to derive new conclusions which are not derivable from the old information or from the new information alone (contextual implication), by providing new evidence for new assumptions (contextual strengthening), or evidence against old assumptions (contextual erasure). Relevance is a matter of degree. The mental effort required to process the information, that is, the length of the chain of reasoning and deductive rules 
that are required, has to be part of the computation together with the contextual effects. The greater the contextual effects, and the lesser the processing effort required to obtain them, the greater the relevance. The heart of Relevance Theory is the principle of relevance, according to which "every act of ostensive communication communicates a presumption of its own optimal relevance” (Sperber and Wilson 1995:158). This means that every utterance comes with a guarantee of optimal relevance; in other words, it provides the hearer with the guarantee that whatever the communicator is trying to tell him will be relevant. The principle of relevance is seen as the only one needed to explain human communication. Sperber and Wilson understand inferential communication as, first of all, a manifestation or an “ostension”, of the communicator's intention to communicate something. Once this intention has been recognised, the principle of relevance makes sure that the hearer works out what information it might be that the speaker intends to communicate - the most relevant one, the one that produces most contextual effects with the least possible effort.

We argue that pragmatic relevance plays a role in middle acceptability. The different degree of acceptability shown by the following sentences can be put down to the fact that (5b) is more relevant than $(5 \mathrm{a})$ :
a. *John's article reads.
b. John's article reads very well.

It is difficult to see how (5a) could be relevant at all, that is, how it can be made to interact with old information and produce any contextual effects. It is a well-known, undisputed fact that articles are there to be read, and no new conclusions could be obtained by stating it, and neither can any previously held assumptions be strengthened or erased. Saying that an article reads well, on the other hand, may come to contradict an existing assumption if, for example, our belief so far had been that John's article was a particularly tough one to read, or it may come as completely new information if we simply had no previous knowledge of whether John's article was easy or difficult to read. In a nutshell, (5b) is more relevant than (5a). It is now a matter of testing empirically whether it is indeed the case that pragmatic relevance makes a real difference in middle acceptability.

How exactly will we do this? Given that pragmatic relevance is a context-dependant notion, it becomes necessary to somehow objectify linguistically the representation of the context. We will do this by resorting to adverbial modification and to the definiteness of the middle subject noun phrase. Both constitute linguistic strategies that help to bring in the contextual assumptions that contribute to middle acceptability. The case of adverbial modification has just been exposed in example (5). A similar reasoning applies to definiteness. The difference in acceptability between the following two sentences, which 
differ minimally with respect to the definiteness of their subject, lends itself to an analysis in terms of pragmatic relevance.
a. ? A book sells well.
b. This book sells well.

The use of the deictic determiner in (6b) brings in "environmental information" (Sperber \& Wilson, 1995:141), thanks to which greater contextual effects can be created at lesser processing cost than in example (6a), where it is more difficult to see what the contextual assumptions could be with which the new information could interact to produce contextual effects. In other words, it is difficult to construe a context where (6a) could be relevant.

Our hypothesis that middle acceptability is affected by relevance will thus be effectively tested by investigating two further, separate hypotheses. We will investigate whether the presence of an adverb can be demonstrated to increase middle acceptability, and to what extent. Similarly, we will test whether any, and what, difference in acceptability exists between middles with definite subjects and those with indefinite ones.

Summing up, we will be testing for the role that aspectuality, affectedness, adverbial modification and definiteness of the subject play in middle acceptability. Instead of a model of traditional binary judgments, which sorts data categorically as either grammatical and ungrammatical, we will be adopting a theory of competence that allows for gradient data and degrees of acceptability, as posited by Keller (2000), Bauer (2001) and Sorace and Keller (2005). Bauer presents a model that distinguishes between absolute constraints, which belong to the language system, and variable constraints, which relate to the way language is used and, very importantly for the purposes of this paper, may be subject to "extra-systemic factors" (Bauer 2001:205ff.). Keller (2000) and Sorace and Keller (2005) also account for gradient data by setting up a constraint-based model. They argue that linguistic constraints come in two types: hard constraints, whose violation leads to strong unacceptability and triggers categorical acceptability judgments, and soft constraints, whose violation leads only to mild unacceptability and induces gradience. Their model is technically more complex that Bauer's, but the linguistic insight is the same, namely, the recognition that less than perfect data also have grammatical status and that there are discoverable factors why that should be so.

\section{METHODOLOGY}

Acceptability judgments were obtained by means of a written questionnaire. A list of 32 middle sentences was constructed. It was designed in such a way as to permit that each 
hypothesis be tested individually by comparing two sets of four middles differing minimally with respect to each of the factors under investigation (aspectuality, affectedness, adverbial modification and definiteness of the subject). The list of 32 middles was thus made up of four middles for each of the factor combinations. The list of middle sentences used, together with the mean acceptability rating each one received, appears in the Appendix. In order to test for the effect of affectedness on middle acceptability, for example, it was possible to compare four middle sentences with affected subjects with four middle sentences with unaffected subjects (groups 1 and 5). The rest of the factors were kept constant and they were also “optimized”, that is, as far as possible, middles formed from accomplishments, with a definite subject and with adverbial modification were used, since we hypothesise that, if any difference is to be found at all, these would be the features to make better middles. Aspectuality is a four-way variable rather than a binary one, so there were four groups for comparison, each differing minimally in their aspectual category: four accomplishments, four activities, four achievements and four states. Again, the rest of the factors were kept constant, although this was not possible in the case of states, which are incompatible with affected objects and two of the achievement sentences also had an unaffected subject. As for definiteness of the subject, four sentences whose subjects were deictic expressions (group 1) were considered against the same number of middles with indefinite subjects (group 7), all of them being otherwise accomplishments, with affected subjects and adverbial modification. Adverbial modification was dealt with in an identical manner, by comparing sets 1 and 6 . Using two separate tests to validate what is ultimately a single hypothesis - that middle acceptability is affected by pragmatic relevance - might seem redundant, but will, we expect, serve to strengthen the robustness of our results. More interestingly, it allowed us to introduce an additional set of four middle sentences (group 8), characterised by both the lack of adverbial modification and the indefiniteness of the subject, while the features "accomplishment" and "affectedness" remain unaltered. Recall that relevance is a matter of degree and we expect that acceptability judgments for these middles will enable us to formulate some conclusions in this direction.

The questionnaire contained 100 sentences in all, 32 middles plus 68 filler sentences. It was presented to 20 native speakers of British English. In total, 640 middle tokens were analysed. Speakers were asked to rate the acceptability of the sentences on a scale of 1 to 5 , where 1 was the worst possible rating, and 5 the best. They were specifically instructed to judge the sentences as they were presented to them and to assume no further context. 


\section{RESULTS}

\subsection{Aspectuality}

The following table shows the mean of the acceptability ratings obtained for middles formed from each aspectual class of verb phrases. The statistical analysis has been carried out by comparing the mean score obtained by each group against the mean score obtained by each of the other groups ${ }^{1}$.

Clear differences in acceptability seem to exist between middles formed from different aspectual classes, and they are all significant at the 0.5 level. We can therefore conclude that whether a middle sentence is formed from an accomplishment, or an activity, or an achievement or a state does have an influence on its degree of acceptability.

\begin{tabular}{|l|c|}
\hline \multicolumn{1}{|c|}{ Aspectual class } & Rating /5 \\
\hline Accomplishments & 3.9 \\
\hline Activities & 3.5 \\
\hline Achievements & 2.7 \\
\hline States & 1.3 \\
\hline
\end{tabular}

[Acc.-Act.] $\mathrm{p}<0.05$ for 158 d.f. and $\mathrm{t}=2.007$, [Acc.-Ach.] $\mathrm{p}<0.001$ for 158 d.f. and $\mathrm{t}=6.3$, [Acc.- Sta.] $\mathrm{p}<$ 0.001 for 158 d.f. and $t=16.2$, [Act.-Ach.] $\mathrm{p}<0.001$ for 158 d.f. and $t=4.49$, [Act.- Sta.] $\mathrm{p}<0.001$ for 158 d.f. and $\mathrm{t}=14.271$, [Ach.- Sta.] $\mathrm{p}<0.001$ for158 d.f. and $\mathrm{t}=8.41$

Table 1: Acceptability ratings depending on the aspectual class of the verb phrase.

\subsection{Affectedness}

The following table shows the mean acceptability ratings obtained for middles in group 1 (e.g. This cheese grates easily), formed from affected predicates, and those in group 5 (e.g. She photographs well. She could be a model), formed from unaffected predicates respectively:

\begin{tabular}{|c|c|}
\hline Affectedness of the middle subject & Rating $\mathbf{5}$ \\
\hline Affected & 3.9 \\
\hline Unaffected & 3.5 \\
\hline
\end{tabular}

$\mathrm{p}>0.05$ for 158 d.f. and $\mathrm{t}=1.76$

Table 2: Acceptability ratings for middles formed with affected and unaffected predicates.

Middles formed from affected predicates received an average score of 3.9, slightly higher than the score obtained by those middles which were not formed from affected predicates (3.5). The difference is however statistically insignificant and enables us to claim that affectedness does not play a significant role in middle acceptability. This comes to contradict many existing proposals in the literature that link middle formation with the notion of affectedness or change of state. The data presented here show that, in fact, whether a 
middle sentence is formed from a predicate that involves a change of state or not, does not have a significant bearing on its degree of acceptability.

\subsection{Definiteness and adverbial modification}

Let us consider first the difference in the mean acceptability ratings obtained by middles with definite subjects and middles with indefinite subjects. As always, two groups of middles were compared, group 1 (e.g. This cheese grates easily) and group 7 (e.g. A shirt irons easily). They differed only with respect to the definiteness of the subject, all other factors being kept constant. The mean acceptability ratings for both groups can be seen in the following table:

\begin{tabular}{|l|c|}
\hline \multicolumn{1}{|c|}{ Subject NP } & Rating /5 \\
\hline Definite subject & 3.9 \\
\hline Indefinite subject & 2.6 \\
\hline
\end{tabular}

$\mathrm{p}<0.001$ for 158 d.f. and $\mathrm{t}=3.9$

Table 3: Middle acceptability depending on the definiteness of the subject.

Middles with definite subjects obtained an average score of 3.9, against the much lower 2.6 average rating of middles with indefinite subjects. The difference between both means is statistically significant and we can conclude that definiteness of the middle subject does make a real difference in middle acceptability.

As for adverbial modification, the following table shows how middles with adverbial modification (e.g. This cheese grates easily) compare to middles without adverbial modification (e.g. This meat cuts):

\begin{tabular}{|l|c|}
\hline Presence of adverbial modification & Rating /5 \\
\hline With adverb & 3.9 \\
\hline Without adverb & 1.7 \\
\hline
\end{tabular}

$\mathrm{p}<0.001$ for 158 d.f. and $\mathrm{t}=12.5$

Table 4: Acceptability ratings depending on the presence of adverbial modification.

Again, the contrast is stark. Middles without adverbs receive the very poor average score of 1.7 , compared to those middles that were equal to them in all respects except in the presence of adverbial modification, whose average score was 3.9. The difference is statistically significant, which confirms our predictions that adverbial modification does affect middle acceptability.

As we explained in our pre-analysis, the influence of adverbial modification or definiteness on middle acceptability cannot be taken at face value. They cannot be understood as restrictions on the presence of a definite article or adverbial modification as such. Given 
the right context, a middle sentence with an indefinite article, or without an adverb, might be perfectly acceptable. Rather, we took them to be linguistic devices that contribute to bringing about contextual effects, and thus enable us to decide whether middle acceptability is subject to a pragmatic constraint on relevance, which we have now shown to be the case. What is more, since relevance was a matter of degree, we expect that, the greater the irrelevance of a middle sentence, the higher its degree of unacceptability. Observe the following table:

\begin{tabular}{|l|c|}
\hline \multicolumn{1}{|c|}{ Degree of relevance } & Rating /5 \\
\hline Adv + def. art. & 3.9 \\
\hline Adv + indef. art. & 2.6 \\
\hline No adv. + def. art. & 1.7 \\
\hline No adv. + indef. art & 1.4 \\
\hline
\end{tabular}

Table 5: Effect of degree of relevance on middle acceptability

This shows the different degrees of acceptability of 4 groups of middles which differ minimally with respect to adverbial modification and definiteness of the article, as indicated in the labels for each line (groups 1, 6, 7 and 8). The first thing to note is that the lack of adverbial modification leads to a higher degree of unacceptability than indefiniteness of the subject. When the adverb is withheld (e.g. This meat cuts), the mean acceptability score drops dramatically from 3.9 to 1.7 , but only to 2.6 when the definite article is replaced by an indefinite one (e.g. A shirt irons easily). This lends support to our view of adverbs as the context-conducive devices par excellence and also to our pragmatically-motivated analysis of adverbs as an intrinsic part of the middle construction. Once the connection between relevance and middle acceptability has been established (see the rest of the discussion in the next paragraph), the fact that adverbial modification is so common in middles and indeed perceived as an integral part of the construction is in turn easily explained: adverbial modification makes it particularly easy to derive contextual effects, a requirement on which the acceptability of middles has been shown to rely. This is particularly well evidenced by the contrast in acceptability between minimal pairs like This meat cuts easily, with an average score of 4.1 and This meat cuts, which receives a score of 1.6.

Secondly, we note that the lowest score (1.4) is obtained by the group of middles with neither adverbial modification nor definite article, such as $A$ shirt irons. This comes to confirm our hypothesis that middle acceptability is indeed affected by relevance, since it is sensitive to the fluctuations in degree of relevance. It is highest when the possibility of deriving contextual effects increases, that is, when both an adverb and definiteness are present, but decreases as the possibilities of deriving contextual effects become more costly, in processing terms, that is, when either the adverb or definiteness is not present, or when both are lacking, in which case acceptability plummets to $1.4 .^{2}$ Our hypothesis is further confirmed by calculating Pearson's correlation coefficient (r), which has a value of $0.639 .^{3}$ 
For $\mathrm{r}(318)=0.639, \mathrm{p}<0.001$. The correlation is significant well beyond the $5 \%$ level, so we can reject the null hypothesis that the association of relevance with acceptability has arisen purely by chance, and state instead that there is a correlation between the two variables: the higher the relevance, the higher the acceptability.

To sum up, these data have provided us some empirical basis on which some important claims about the restrictions on middle acceptability can begin to be made. Except for affectedness, all the other factors we have investigated have been shown to play a role in middle acceptability, and, for ease of exposition, can be formulated as follows:

(7) Constraints on middles

a. Activity (Activ): A middle cannot be formed from a predicate marked [+ACTIVITY].

b. Achievement (Achiev): A middle cannot be formed from a predicate marked [+ACHIEVEMENT].

c. Relevance (REL): A middle has to be pragmatically relevant.

d. State (STATE): A middle cannot be formed from a predicate marked [+STATE].

\subsection{The ranking of constraints}

It will have become apparent from the figures we presented in the previous sections that not all restrictions are equally serious or important, in the sense that some constraint violations lead to a higher degree of unacceptability than others. Keller (2000) refers to this as constraint ranking, and claims it to be an essential property that characterises the constraints that account for gradient data.

The ranking of the various constraints that determine middle acceptability can be best observed in Table 6. It shows, in descending order, the mean acceptability ratings of each of the groups of middles in which each of the constraints in (7) was violated, that is, the mean score of those middles which violated ACTIV (group 2), those which violated ACHIEV (group 3), and those that violated STATE (group 4). The score for middles violating REL was the mean score of group 8 (middles without adverb and with indefinite subjects), which was the group of middles exhibiting the highest degree of irrelevance we could control for. The table also shows the average score of those middles that did not violate any of the constraints, and which obtained the highest degree of acceptability, namely, those in group 1. 


\begin{tabular}{|l|c|}
\hline Constraint violation & Rating /5 \\
\hline None & 3.9 \\
\hline Activ & 2.6 \\
\hline Achiev & 1.7 \\
\hline Rel & 1.4 \\
\hline State & 1.3 \\
\hline
\end{tabular}

Table 6: Constraints on middle acceptability

The highest degree of acceptability (3.9) is obtained by those middles that do not violate any constraint. They are followed first by middles which incur a violation of ACTIV, with a rating of 3.5 and then by those middles which violate ACHIEV, with a rating of 2.7. A violation of REL leads to an even lower degree of acceptability (1.4), almost as low as the one obtained by middles which violate STATE, which receive an average score of 1.3. In fact, the difference between the degrees of unacceptability incurred by a violation of REL and a violation of STATE is statistically insignificant ${ }^{4}$. These data give us information, for one thing, about the ranking of the different constraints: STATE is ranked on the same level as REL, because a violation of STATE leads to a virtually identical degree of unacceptability as a violation of REL. REL and STATE are ranked higher than ACHIEV since a violation of either of any of the former two constraints leads to a higher degree of unacceptability than a violation of the latter. ACHIEV is in turn ranked higher than ACTIV, for the same reason ${ }^{5}$. More interestingly, the data also give us valuable information about the weight of the constraints (Keller 2000:252), that is, about how much more important a given constraint is than another one. If what we are doing is trying to account for the gradience in the data, there would actually be little point in saying that a constraint is more serious than another one, unless we also take into account what both constraints' absolute levels of seriousness are, that is, what degree of unacceptability the violation of each of them causes. In our data it is clear that STATE and REL are both very "heavy" (highly ranked) constraints, since they cause a very high degree of unacceptability, whereas ACHIEV and ACTIV are much "lighter" (or lower ranked) constraints, since, when violated, they cause a less serious level of unacceptability.

It is already possible to make some linguistic sense of these data. STATE is a prime candidate for hard constraint status. As we observed in Table 6, middles formed from states receive an average score of 1.3 , which is virtually a categorical rating of 1 , the highest possible degree of unacceptability. It is thus possible to claim that middles formed from states are ungrammatical. The requirement for middles not to be formed from predicates marked [+STATE] can be seen as part of the language system, as Bauer (2001:207) puts it, and can be built into the very grammatical nature of middles. The situation with ACHIEV and ACTIV is very different. The violation of ACHIEV causes a much milder degree of unacceptability, a very middle-ground score (2.7), and can thus be classed as a variable or soft constraint. The 
same goes for ACTIV, whose violation causes an even smaller degree of unacceptability when violated, middles formed from activities scoring 3.5. This means that middles formed from achievements or activities are indeed possible middles, and certainly not ungrammatical or excluded by the system, but simply slightly unacceptable.

The status of REL as a constraint is somewhat more problematic. It is a very highlyranked constraint. When it is violated, as in our middles without adverbial modification or definite article, an extremely high degree of unacceptability is obtained (1.4), one that is practically as high as the one that results when STATE is violated (1.3). It would also seem an ideal candidate to be classified as an absolute constraint. What is then preventing us from saying that REL is an absolute constraint?

Recall, in the first place, that relevance is a matter of degree. It is thus inaccurate to say that a violation of REL causes strong unacceptability. By investigating the reduction in acceptability caused by a violation of REL as a constraint, we are de facto analysing the correlation between the degree of relevance of a middle sentence and its acceptability, as discussed above. As we noted then, the claim should go along the lines of "the more irrelevant a middle, the less acceptable it is". It is true that when relevance is very low, as in middles without definite article or adverbial modification, acceptability is very low, as low as when a hard constraint, like STATE, is violated. But it is also true that, as soon as the degree of relevance increases, acceptability improves, as the data presented in Table 5 showed. It is, in sum, logically impossible to have an intrinsically variable restriction determining categorically what a middle sentence can or cannot be. From this point of view REL cannot be an absolute constraint, but must be a soft or variable one. And of course, from a more linguistic point of view, too, it would be odd to classify REL as a hard constraint. If relevance is a matter of degree, that is because it is essentially context-dependent. It is in effect making the acceptability of middles correlate with situational factors and information about the world.

It should be noted that whereas the degree of unacceptability caused by a constraint violation is the key aspect that distinguishes a hard from a soft constraint, it is not the only one. Keller (2000) and Sorace and Keller (2005) investigate other correlates of the hard/soft dichotomy and conclude that both types of constraint also differ with respect to contextual effects: hard constraint violations are equally unacceptable in all contexts, whereas the degree of unacceptability triggered by a soft constraint violation can vary from context to context. This is consistent with our classification of REL as a soft constraint, since REL is directly dependant on the context. We could even say that it is the context, as the previous paragraphs made clear. It is also consistent without typological classification of the other constraints. Of course, context being one of the constraints, investigating whether the degree of acceptability incurred by a constraint violation varies from context to context amounts to investigating the effect that the interaction of constraints has on acceptability. García de la Maza (2005) presents data from an experiment measuring the effect that the interaction of constraints has 
on middle acceptability. She shows that, when either of the two aspectual constraints cooccurs with a violation of REL to the maximum degree, acceptability is maximally low too ${ }^{6}$. This shows that, as soft constraints, ACHIEV and ACTIV “depend” on REL. On the other hand, we saw that, when a violation of ACHIEV or ACTIV takes place in a maximally relevant context, that is, when only ACHIEV or ACTIV, but not REL, are violated, acceptability is very high too, although the effects of the aspectual constraints can already be felt then: when ACHIEV is violated, a lower degree of acceptability will be obtained than when AcTIV is violated, which will in turn result in a lower degree of acceptability than when no aspectual constraint is violated, as shown in Table 6. Equally, we expect that a mild degree of relevance combined with a violation of one of the other two constraints, ACHIEV or ACTIV, will also result in a mildly acceptable sentence, although, again, relative differences will exist according to which of the two aspectual constraints is violated, the degree of unacceptability being higher if the constraint that is violated is ACHIEV than if it is ACTIV. We do not have data to support this last claim, but, given the picture just outlined, and given also the fact that fluctuating degrees of relevance in middles formed from accomplishments were shown to yield fluctuating degrees of acceptability (Table 5), it is reasonable to expect the degree of unacceptability of a middle sentence to fluctuate equally when varying degrees of relevance go hand in hand with a violation of ACHIEV or ACTIV.

It will have become clear by now why it is not accurate to say that REL strictly dominates the aspectual constraints. It is not the case that the degree of acceptability of a middle sentence is determined exclusively by its degree of relevance. Had this been the case, we would not have found the different degrees in acceptability that middles formed from accomplishments, activities and achievements displayed amongst themselves, despite the fact that they all had definite subjects and adverbial modification (Table 6). A more accurate way to put it would thus be to say that REL overrides or takes precedence over the aspectual constraints. It decides first whether there are any chances for a middle to be acceptable at all, and what those chances are. The aspectual constraints then come into play and act on that by imposing their own share of reduction of acceptability on whatever the degree of acceptability it is that has been previously decided by REL. REL has thus emerged as being the key to determining middle acceptability, and we can safely conclude that the gradience in middle acceptability proceeds largely along an axis of pragmatic relevance.

\section{DISCUSSION}

Note the contrast between the examples in (8) and (9): 
A: What have you been up to this week?

B: In 1969 man stepped on the moon.

This book reads.

Both B's reply in (8) and the middle in (9) could be said to violate a pragmatic principle, the principle of relevance, although with very different consequences in each case. In (8), the irrelevance of B's response leads to a breakdown of the communicative act, but the sentence is otherwise perfectly well-formed and any native speaker of English would have no problem in accepting it as a good sentence of English. In the case of the middle in (9), as we know, lack of pragmatic relevance leads to a reduction in acceptability and many speakers of English, when confronted with it, would say that it is "bad English", as the data presented in this article have shown. The contrast can be explained by distinguishing two types of pragmatics, as Goldberg (2004:428) does: non-conventional and conventional pragmatics. By unconventional pragmatics she refers to "the effects of the comprehension or production of sentences in particular contexts of use by actual language users”. Unconventional pragmatics is basically conversational pragmatics, the study of the principles that govern verbal communication and inference. By conventional pragmatics, on the other hand, Goldberg understands "the conventional association of certain formal properties of language with certain constraints on pragmatic contexts”. Non-conventional pragmatics accounts for the communicative breakdown caused by B's response in (8), which does not respect the principle of relevance. The unacceptability of (9), on the other hand, is accounted for by the fact that the very same conversational principle, the principle of relevance, has become deeply "conventionalised" as part of the syntactic construction. This happens according to the following logic. It is part of the semantics of middles that they are property-predicational constructions. On hearing a middle like that in (9), it is however impossible to infer from the context (which in this case is non-existent), what the property of the book could be that makes it readable. Books, under normal circumstances, can be read and there is no relevance in stating it. The unacceptability of middles by virtue of their irrelevance thus results from the impossibility of reconciling what the sentence means with what the context allows us to infer is implicated by it. Conversely, an acceptable middle is one for which the context allows us to infer that a relevant property is being attributed to the subject. Those potential inferences from the context can thus be said to be grammaticalised or conventionalised (Green, 2004: 412; Kay, 2004: 677) into the middle construction itself in such a way that it is reasonable to expect of middles that they are only used to predicate a relevant property of their subjects, and are otherwise unacceptable and not merely conversationally infelicitous. In other words, conditions on the use of the middle construction have permeated deeply into the construction itself and become conditions on its acceptability. 
Green (2004:411) gives some examples of constructions in which a similar phenomenon can be observed. Consider the following two sentences (her examples):

(10) The Celtics play the Bucks tomorrow.

(11) \# The Celtics crush the Bucks tomorrow.

The present tense can be used in English for future time reference as long as the event referred to can be understood to be pre-arranged, as in (10), where the game can be assumed to have been scheduled and arranged in advance. It is, however, not possible to know in advance what the outcome of the game will be, unless, as Green points out, the game is known to have been fixed. The unacceptability of (11) thus results from the contradiction in using a structure that is strongly linked to conditions on use, "and then deny that those conditions hold" (Green 2004:411).

As still another instance, she mentions the case of subject-auxiliary inversion in embedded questions, as in (12), which can be used in many dialects only when it is presupposed that the answer to the question implied by the embedded clause is not known by whoever is interested in that answer. Otherwise, as in (13), the sentence is unacceptable (Green's examples). Again, there are aspects of the use of the construction that are deeply tied to the construction itself. The unacceptability of (13) results from the incompatibility between what the sentence is trying to assert and what can be inferred by the hearer from the use of this type of construction.

(12) She wants to know who did I appoint.

(13) \# She already knows who did I appoint.

Finally, consider the following bare passive example discussed by Goldberg (2004:438)

(14) \# The house was built.

Goldberg argues that sentence (14) is anomalous and that this is due to the fact that the sentence is uninformative, and that not very relevant inferences can be drawn by stating simply that something was created in the usual way. This is at odds with our expectations that passives should be used to present the patient as topic, or to avoid giving information about the agent, or to present the action as having a particular effect on the patient (Jespersen 1924:167-8), as (15) or (16) successfully do: 
(15) The house was built in three days.

(16) The house was demolished.

These three cases are indeed illustrative of the conventionalisation of pragmatic factors as constraints on acceptability. However, they do not come with any supporting evidence, in the form of acceptability judgments that indicate how unacceptable examples (11), (13) and (14) are. Neither do they show experimentally that their unacceptability is indeed, and primarily, due to pragmatic motives. The reason this evidence is important is that it is reasonable to expect that the grammaticalisation of pragmatic conditions can happen to different degrees in different constructions (Levinson 2000:264, 266). We can detect those degrees by observing the level of unacceptability of those sentences which do not comply with those conditions as well as the way in which those conditions interact with one another and how this affects acceptability. We suspect conditions on use are very much an intrinsic part of structures which combine present tense with future time adverbs, as well as of structures that invert subject and auxiliary order in embedded questions, though not so much of bare passives like those in (14). In the case of middles, however, we do have such evidence. The very heavy weight of REL as a constraint, and the manner in which it works, determining first and foremost the degree of acceptability of a middle sentence, are indications of the extreme degree to which conditions on use are grammaticalised, or ingrained into the middle construction and point to the essentially "pragmatic value" (Green 2004:407) of the middle construction.

One of the most immediate consequences of understanding that pragmatic conditions may be conventionalised into certain syntactic structures is that many of the formal properties of sentences which had previously been put down to syntactic constraints now need to be restated in pragmatic terms (Levinson 2000:261ff.; Green 2004:407). The obvious implication of this pragmatically minded approach for a structural analysis of the middle construction concerns the treatment of adverbial modification. The difference in acceptability between middles with or without adverbial modification, exemplified again under (17) and (18), has led pragmatically-unaware linguists to propose that adverbs are an obligatory part of the middle construction and to account for it in strictly syntactic terms.

(18) This article reads well.

Hoekstra and Roberts (1993:192ff.), for example, argue that the suppressed subject argument in a middle sentence is a pro which needs to be "theta-licensed for content". This requirement is satisfied by adverbs like easily, whose Experiencer theta-role is identified with pro. This account predicts that examples like (17) are ungrammatical, since lack of adverbial 
modification means that pro is left unlicensed. At the same time, it breaks down when confronted with sentences like (19), found in an article discussing the health risks of cereals that contain too much sugar. It also discusses the convenience of reducing the sugar content of those cereals specifically targeted at children. However...

(19) The reality is that sweet cereal sells. (Sheila Keating, The Times Magazine, $15^{\text {th }}$ May 2004, p.81)

On the other hand, once we understand the pragmatic nature of middles, we come to realise that adverbs are not compulsory in middle sentences and no syntactic machinery of the sort just illustrated needs to be devised to account for them. Accounting for adverbial modification in middles in derivational terms is as misguided as would be to posit a rule that prevents middles from having indefinite subjects in order to account for the unacceptability of (20), given the (increased) acceptability of examples like (21):

(20) ? A book sells well.

(21) A book sells well if it is marketed properly.

Adverbs are simply preferred in middles for pragmatic reasons. The unacceptability of a middle like (9) results from its irrelevance, from the impossibility of inferring from the context what the relevant property could be that the speaker is trying to attribute to the subject, which is why the middle construction was used in the first place. We know that adverbs like easily increase the chances of making such inferences.

Pragmatically-aware linguists, as we now are, at least as far as the middle construction is concerned, would thus say that sentences like (9) or (20) are not ungrammatical, but simply unacceptable, and that their unacceptability is due to pragmatic reasons. Saying this is conceptually a step ahead of saying that they are only pragmatically or conversationally odd. The conceptual gap is filled in by the notion of the conventionalisation of pragmatic properties.

\section{CONCLUSION}

This paper has come to highlight some of the ill-founded assumptions that underlie much of what has been said about the issue of the restrictions on middles. These have to do firstly, above all, with the lack of concern for real data and with the categorisation of middles as either fully grammatical or fully ungrammatical. Existing accounts of the restrictions on middles have also been exceedingly endocentric. They search for solutions by looking 
exclusively into the internal structure of middles and disregard the possibility that syntaxexternal factors might also have something to say about the characteristics of the construction and about what a middle sentence can or cannot be. Our analysis has tried to rectify these deficiencies. It has been based on the elicitation of speakers' acceptability judgments, on the notion of gradience, and on a consideration of aspects of the use of middles and not of language-internal aspects only.

\section{NOTES}

1. A t-test, from Woods, Fletcher and Hughes (1986:176-7) was used here and in subsequent tests.

2. From now onwards, all measures of differences between two means have been statistically tested for significance, and are significant unless otherwise stated. The precise values for $t$ in each case will only appear in footnotes, for the sake of fluidity of exposition in the main text. In Table 5, the difference between the score of the 'Adv+Def' group and the 'Indef' group was already shown to be significant, as well as the difference between 'Adv+Def' and 'No adv'. The difference between the scores of the 'No Adv' and 'No Adv+Indef' is also significant: for 158 d.f. and t = 2.47, $\mathrm{p}<$ 0.02. For the difference between the scores of the 'Adv+Def' and 'No adv+Indef' groups, $\mathrm{p}<$ 0.001 for 158 d.f. and $t=15.57$. For the difference between the score of the 'No Adv+Indef' and the 'Indef' group, $\mathrm{p}<0.001$ for 158 d.f. and $\mathrm{t}=7.8$. For the differences between the scores of the 'Indef' and 'No adv', $\mathrm{p}<0.05$ for 158 d.f. and $\mathrm{t}=2.25$.

3. For details of the correlation test see Morgan, Griego and Gloeckner (2001: ch 7, 9).

4. For 158 d.f. and $t=0.125, p>0.05$.

5. For the difference between REL and ACHIEV, $p<0.001$ for 158 d.f. and $t=8.06$. For the difference between REL and ACTIV, $\mathrm{p}<0.001$ for 158 d.f. and $\mathrm{t}=14.4$. All other differences had been tested before.

6. This occurs in sentences formed with achievements or activities without adverbial modification or definite article. For example, in A frisbee throws, both ACHIEV and REL are violated. In A car drives, both ACTIV and REL are violated.

\section{REFERENCES}

Bauer, L. (2001). Morphological productivity. Cambridge: Cambridge University Press.

Comrie, B. (1976). Aspect. Cambridge: Cambridge University Press.

Doron, E. and Rappaport Hovav, M. (1991). Affectedness and externalization. Proceedings of the Annual Meeting of the North Eastern Linguistic Society, 21, 81-94.

Dowty, D. (1991). Thematic proto-roles and argument selection. Language, 67, 547-619.

Erades, P.A. (1975). Points of Modern English Syntax. Contributions to English Studies by P.A. Erades. Amsterdam: Swets and Zeitlinger.

Fagan, S. M. (1992). The Syntax and Semantics of Middle Constructions. Cambridge: Cambridge University Press.

Fellbaum, C. (1989). On the Reflexive Middle in English. Papers from the Annual Regional Meeting of the Chicago Linguistic Society, 25(1), 123-132.

García de la Maza, Casilda (2005). The Grammar, Semantics and Productivity of the English Middle Construction. PhD dissertation, Dept. of Linguistics, University of Cambridge. 
García de la Maza, C. (2011). The Semantics of English Middles and Pseudo-Middles. In P. Guerrero Medina (Ed.), Morphosyntactic Alternations in English: Functional and Cognitive Perspectives (pp. 161-181). Sheffield: Equinox.

Goldberg, A. (2004). Pragmatics and Argument Structure. In L. Horn and G. Ward (Eds.) The Handbook of Pragmatics (pp. 427-441). Oxford: Blackwell.

Green, G. (2004). Some Interactions of Pragmatics and Grammar. L. Horn and G. Ward (Eds.) The Handbook of Pragmatics (pp. 408-426). Oxford: Blackwell.

Hale, K. and Keyser, S. (1987). A view from the middle. Lexicon Project Working Papers 10. Cambridge, Mass.: Centre for Cognitive Science, MIT.

Hoekstra, T. and Roberts I. (1993). Middle Constructions in Dutch and English.' In E. Reuland and W. Abraham (Eds.) Knowledge and Language, Volume II, Lexical and Conceptual Structure (pp. 183-220). Dordrecht: Kluwer.

Jespersen, O. (1924). The Philosophy of Grammar. London: Allen and Unwin.

Kay, P. \& Fillmore, C. (2004). Pragmatic Aspects of Grammatical Constructions. L. Horn \& G. Ward (Eds.), The Handbook of Pragmatics (pp. 675-700). Oxford: Blackwell.

Keller, F. (2000). Gradience in Grammar. Experimental and Computational Aspects of Degrees of Grammaticality. PhD dissertation, University of Edinburgh.

Keyser, S. \& Roeper, T. (1984). On the middle and ergative constructions in English. Linguistic Inquiry, 15, 381-416.

Levin, B. (1993). English Verb Classes and Alternations. Chicago: The University of Chicago Press.

Levinson, S. (2000). Presumptive Meanings: The Theory of Generalized Conversational Implicature. Cambridge, Mass.: MIT Press.

Morgan, G., Griego, O. \& Gloeckner, G. (2001). SPSS for Windows. An Introduction to Use and Interpretation in Research. New Jersey: Lawrence Erlbaum.

Roberts, I. (1987). The Representation of Implicit and Dethematized Subjects. Dordrecht: Foris.

Rosta, A. (1995). The Semantics of English Mediopassives. In B. Aarts, Bas \& C. Meyer (Eds.), The Verb in Contemporary English (pp. 123-144). Cambridge: Cambridge University Press.

Sorace, A. \& Keller F. (2005). Gradience in linguistic data. Lingua, 115, 1497-1524.

Sperber, D. \& Wilson D. (1995). Relevance: Communication and Cognition. (2nd Ed.) Oxford: Blackwell.

Van Oosten, J. (1977). Subjects and Agenthood in English. Papers from the Annual Regional Meeting of the Chicago Linguistic Society, 13, 459-471.

Vendler, Z. (1967). Linguistics in Philosophy. Ithaca, New York: Cornell University Press.

Woods, A., Fletcher, P. \& Hughes A. (1986). Statistics in Language Studies. Cambridge: Cambridge University Press.

Yoshimura, K. \& Taylor, J.R. (2004). What makes a good middle? The role of qualia in the interpretation and acceptability of middle expressions in English. English Language and Linguistics 8(2), 293-321.

\section{APPENDIX}

Group 1: accomplishment VP, affected subject, with adverbial modification, definite article:

1. This Spanish wine drinks up very well. (2.1)

2. This door locks easily. (4.8)

3. This meat cuts easily. (4.1)

4. This cheese grates easily. (4.6)

Group 2: activity VP, affected subject, with adverbial modification, definite article:

5. This car drives beautifully. (4.3)

6. This wheelbarrow pushes easily. (3.3)

7. This wheely-bin pulls with difficulty. (2.4)

8. Her hair combs easily. (4.1) 
Group 3: achievement VP, (un)affected subject, with adverbial modification, definite article:

9. This frisbee throws easily. It was very expensive! (3.3)

10. This type of mistake spots easily. (1.5)

11. This suitcase lifts up very easily. It's got one handle on each side. (3.7)

12. This flat rents out very well. (2.4)

Group 4: state VP, unaffected subject, with adverbial modification, definite article:

13. I have no doubts about her. She trusts easily. (1.7)

14. This safe combination remembers easily. (1.4)

15. The answer knows easily. (1.1)

16. John is nice and cheerful. He likes easily. (1.3)

Group 5: accomplishment, unaffected subject, with adverbial modification, definite article:

17. She photographs very well. She could be a model. (4.7)

18. This signature forges easily. (2.2)

19. She interviews very well. She will never dodge any of the questions you ask her. (4.3)

20. This book reads easily. (2.9)

Group 6: accomplishment VP, affected subject, without adverbial modification, definite article:

21. This jumper washes. (2.1)

22. This shirt irons. (2.0)

23. This meat cuts. (1.6)

24. This thesis writes. (1.2)

Group 7: accomplishment VP, affected subject, with adverbial modification, indefinite article:

25. A door locks easily. (3.7)

26. A room paints easily. (1.7)

27. An animal kills easily if you have the right weapon. (1.9)

28. A shirt irons easily. (3.2)

Group 8: accomplishment VP, affected subject, without adverbial modification, with indefinite article:

29. A shirt irons. (1.6)

30. A jumper washes. (1.7)

31. A thesis writes. (1.1)

32. A lemonade drinks. (1.1) 